\title{
Evidence for a Potential Role for HDL as an Important Source of Cholesterol in Human Adrenocortical Tumors Via the CLA-1 Pathway
}

\author{
Hitomi IMACHI, KoJI MURAO, YoshitAKa SAYO, Hitoshi HOSOKAWA, \\ MAKoto SATO, Michio NIIMI*, SHOJI KOBAYASHI**, AKIRA MIYAUCHI***, \\ TOSHIHIKO ISHIDA, AND JIRO TAKAHARA
}

First Department of Internal Medicine, Kagawa Medical University, Kagawa 761-0793, *Central Laboratory, Kagawa Medical University, Kagawa 761-0793,

**First Department of Pathology, Kagawa Medical University, Kagawa 761-0793,

***Second Department of Surgery, Kagawa Medical University, Kagawa 761-0793, Japan

\begin{abstract}
CLA-1, a human homologue of rodent scavenger receptor class B1 (SR-B1), has been identified as a receptor for high density lipoprotein (HDL) and is highly expressed in the adrenal gland. Several studies have indicated that HDL might be a source of cholesterol for steroidogenesis in the adrenal gland. In this study, we show that ACTH and its second messenger cAMP stimulated CLA-1 protein expression in a human adrenocortical cell line. We also determined whether CLA-1 plays an important role in steroidogenesis by investigating CLA-1 expression levels in various adrenal tumors including the adenomas of Cushing's and Conn's syndrome. Western blot analysis showed that CLA-1 expression was much higher in the tumors of Cushing's syndrome than in non-tumor lesions of Conn's syndrome and pheochromocytoma. We were able to detect a strong CLA-1 signal in tumors of Conn's syndrome, too. On the other hand, much less CLA-1 expression was detected in Cushing's adenoma adjacent adrenal glands. The immunohistochemical analysis showed that CLA-1 was expressed in the outer region of the adrenal cortex mainly in plasma membranes of the cortical cells but not in the medulla. These findings demonstrated for the first time that ACTH increased CLA-1 protein in cultured human adrenocortical cells, and that cortisol- and aldosterone-secreting adenomas had high CLA-1 proteins in their cell surfaces.
\end{abstract}

Key words: CLA-1, HDL, Adrenal gland, ACTH, Steroidogenesis

(Endocrine Journal 46: 27-34, 1999)

SEVERAL reports have suggested that scavenger receptor class B1 (SR-B1), is an attractive candidate receptor for selective cellular high density lipoprotein (HDL) cholesterol ester uptake [1-3]. The high levels of expression of SR-B1 in steroidogenic tissues and the importance of

Received: May 29, 1998

Accepted: October 2, 1998

Correspondence to: Dr. Hitomi IMACHI, First Department of Internal Medicine, Kagawa Medical University, 1750-1 Ikenobe, Kita-gun, Miki-cho, Kagawa 761-0793, Japan selective uptake of HDL as a source of cholesterol for steroidogenesis raised the possibility that SRB1 may participate in cholesterol delivery to steroidogenic tissues in vivo [3]. Immunofluorescence and immunohistochemical studies have shown that SR-B1 is primarily expressed on the surfaces of steroidogenic parenchymal cells such as the zones fasciculate of the adrenal cortex [4]. Treatment of mice with ACTH, which induces adrenocortical steroidogenesis along with enhanced selective uptake of HDL-cholesterol, increased SRB1 protein expression in adrenocortical cells [5]. 
Human CD36 and LIMPII Analogous-1 (CLA-1) share $81 \%$ sequence homology with hamster SRB1 and therefore most likely represent the same gene [6]. We recently reported that CLA-1 is also functionally related to SR-B1 and may play an important role as a docking receptor for HDL in connection with the selective uptake of cholesterol esters. Similar to SR-B1, CLA-1 is primarily expressed in liver and steroidogenic tissues including the adrenal gland [7].

Cholesterol is a precursor in the synthesis of steroid hormones. Extracellular lipoprotein cholesterol taken up from plasma is an important source of the substrate in most steroidogenic tissues. HDL metabolism is hormonally regulated and produces a physiologic response, i.e. increased steroidogenesis [8]. There are additional situations in which enhanced lipoprotein cholesterol consumption by steroidogenic tissues have been suggested to diminish circulating cholesterol levels, such as with steroidogenic tumors [9].

In the present study, we have examined the expression and hormonal regulation of CLA-1 in a human adrenocortical cell line. The expression of CLA-1 in the steroidogenesis of adrenal tumors was analyzed by reverse transcription polymerase chain reaction (RT-PCR), immunoblotting, and immunohistochemistry. CLA-1 was significantly overexpressed in the adenomas of Cushing's syndrome, suggesting that CLA-1 may play an important role in the steroidogenesis of adrenal glands.

\section{Materials and Methods}

\section{Patients}

The tissues investigated in the present study were taken from patients affected by the following adrenal tumors: five of Cushing's adrenal adenomas, two of aldosterone-producing adenomas (Conn's syndrome), three of pheochromocytomas and adjacent tissues. The diagnoses were made on the basis of clinical, biochemical, and morphological data. Tissues were collected after surgical removal, snap-frozen immediately in liquid nitrogen, and stored at $-80^{\circ} \mathrm{C}$, or were fixed in $4 \%$ formalin for 1 day at room temperature, processed, and embedded in paraffin.

\section{$R N A$ isolation and RT-PCR analysis}

Total RNA was isolated from several adrenal tumors and SW-13 cells by single-step acid guanidinium thiocyanate-phenol-chloroform extraction [10]. CLA-1 expression was determined by PCR analysis of the reverse transcribed RNA as described previously $[7,11]$. A primer pair matching the published sequence [6] of CLA-1 (sense; $5^{\prime}$-ATG-ATC-GTG-ATG-GTG-CCG-TC- 3' and antisense; 5' -ACT-GAA-CCT-GCA-GGT-GCTGA- 3') but with no homology with CD36 was used to amplify a $930 \mathrm{bp}$ fragment. As a control, $\beta$-actin was amplified and analyzed under identical conditions using the appropriate set of primers [12]. Human ACTH receptor expression was detected by RT-PCR analysis as described previously [13].

\section{Cell culture}

A human adrenocortical cell line, SW-13 (NIHS, JCRB9069) was plated in Leibovitz's L-15 (L-15) medium (Gibco Lab) supplemented with $10 \%$ fetal calf serum, $100 \mu \mathrm{g} / \mathrm{m} l$ streptomycin and 100 units/ $\mathrm{m} l$ penicillin. After overnight incubation in a humidified atmosphere containing $5 \% \mathrm{CO}_{2}$, the medium was replaced with L-15 medium with or without $0.1 \mathrm{nM}$ to $1 \mu \mathrm{M}$ of ACTH or $10 \mathrm{nM}$ to 1 $\mu \mathrm{M}$ of 8-bromo-cAMP (8-Br-cAMP, Sigma), and incubated for $48 \mathrm{~h}$ before harvesting.

\section{Immunoblotting of adrenal tumors and SW-13 cells}

Membrane fractions were prepared from human samples that had been frozen in liquid nitrogen immediately after harvesting and stored at -80 ${ }^{\circ} \mathrm{C}$ [14]. SW-13 cells were washed and scraped in PBS and lysed in the lysis buffer as described previously [15]. The proteins were resuspended under reducing conditions and $10 \mu \mathrm{g}$ was fractionated by size on $7.5 \%$ SDS-polyacrylamide gels, and transferred to polyvinylidene difluoride (PVDF) membranes for immunoblotting [7]. The membranes were blocked overnight at room temperature with $0.1 \%$ Tween 20 in PBS (PBS-T) containing anti-CLA-1 antibody (diluted 1/3,000 from whole antiserum). The membranes were then washed with PBS-T, incubated for $1 \mathrm{~h}$ at room temperature in PBS-T containing horseradish 
peroxidase-linked anti-guinea pigs IgG (diluted 1/ 3,000 ), rinsed in PBS-T, and antibody binding was visualized by chemiluminescence detection (ECL, Amersham Corp., Arlington Heights, IL). The relative intensities of signals were quantitated by densitometric scanning.

\section{Immunohistochemical localization}

Tissue specimens were fixed in formalin and embedded in paraffin. After deparaffinization and rehydration, the sections were progressively incubated at room temperature for $15 \mathrm{~min}$, with methanol containing $3 \%$ hydrogen peroxide to inhibit endogenous peroxidase activity. Sections were blocked for $60 \mathrm{~min}$ in $10 \%$ normal goat serum (NGS) in PBS, incubated for $2 \mathrm{~h}$ with a guinea pig antibody directed against CLA-1 [7] in 4\% NGS in PBS or with preimmune antibody under identical conditions. Sections were rinsed in PBS, incubated for $30 \mathrm{~min}$ with a biotinylated goat anti-guinea pig IgG (Vectastain Elite Kit, Vector Laboratories, Burlingame, CA) in 1\% NGS in PBS, rinsed in PBS, and incubated with an avidin-biotinylated peroxidase complex (Vectastain Elite Kit) in PBS as suggested by the manufacturer. Antibody binding was visualized with the diaminobenzidine reaction, and sections were counter stained with Mayer's hemotoxylin.

\section{Results}

\section{Expression and regulation of CLA-1 in adrenal cell lines}

Previously we have shown that CLA-1, a human homologue of mouse SR-B1 is expressed at high levels in steroidogenic tissues, especially the human adrenal gland [7]. To determine if the expression of CLA-1 is coordinately regulated with induced adrenal steroidogenesis, we examined the effects of ACTH on CLA-1 expression in the human adrenocortical tumor cell line, SW-13. RT-PCR analysis revealed that $S W-13$ cells expressed the receptor for ACTH (Fig. 1A). In response to ACTH and its second messenger CAMP, CLA-1 was upregulated in SW-13 cells (Fig. 1B and 1C). ACTH and 8-Br-cAMP increased CLA-1 expression in a dose-dependent manner with maximal stimulation
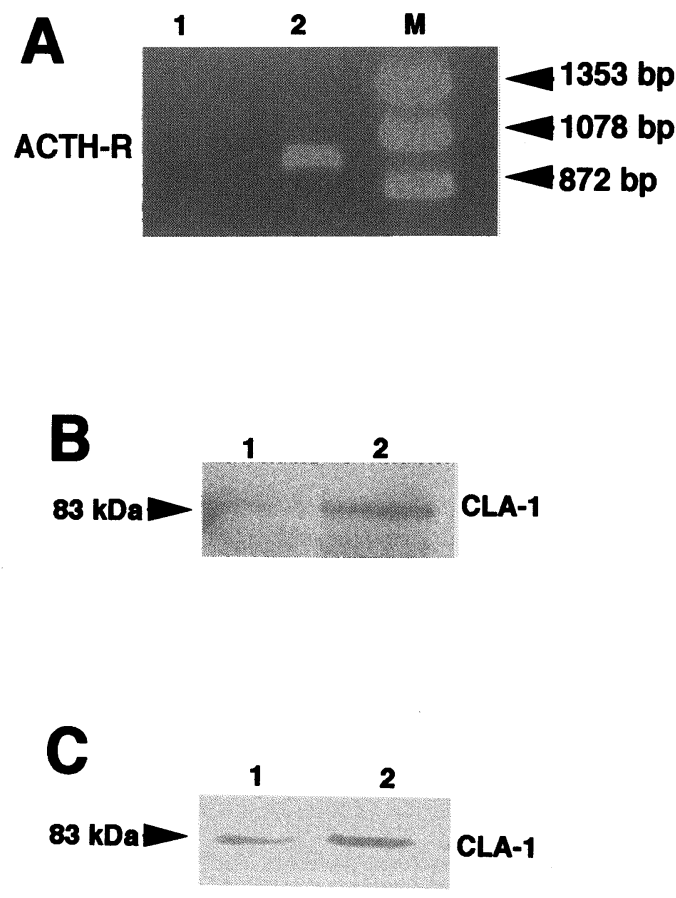

Fig. 1. RT-PCR analysis of $A C T H$ receptor expression in SW-13 cells $(A)$ and effect of ACTH and 8-Br-cAMP on CLA-1 expression in SW-13 cells (B, C). (A) Total RNA was isolated from SW-13 cells without treatment and RT-PCR was performed as described under "Materials and Methods". Lane 1, negative control without reverse transcriptase for lane 2; lane 2, SW-13 cells. The amplified fragments specific to ACTH receptor are indicated. (B) Plasma membrane protein extracts from untreated SW-13 (lane 1) and SW-13 (lane 2) cells treated with $10 \mathrm{nM}$ ACTH were separated by SDS-PAGE electrophoresis, transferred to PVDF membrane, and blotted with anti-CLA-1 antibody. The position of CLA-1 on the gel is indicated by an arrow. (C) Protein extracts from untreated SW-13 (lane 1) and SW-13 (lane 2) cells treated with $1 \mu \mathrm{M}$ 8-Br-cAMP were separated by SDS-PAGE electrophoresis, transferred to PVDF membrane, and blotted with anti-CLA-1 antibody. The position of CLA-1 on the gel is indicated by an arrow.

at a concentration of $10 \mathrm{nmol} / \mathrm{L}$ and $1 \mu \mathrm{mol} / \mathrm{L}$, respectively (data not shown).

\section{Expression of CLA-1 in various adrenal tumors}

We examined 20 human samples for CLA-1 mRNA expression by RT-PCR and CLA-1 protein expression by Western blot (Fig. 2). Using oligonucleotide primers that were designed to amplify a 930 bp portion of CLA-1 cDNA, we 

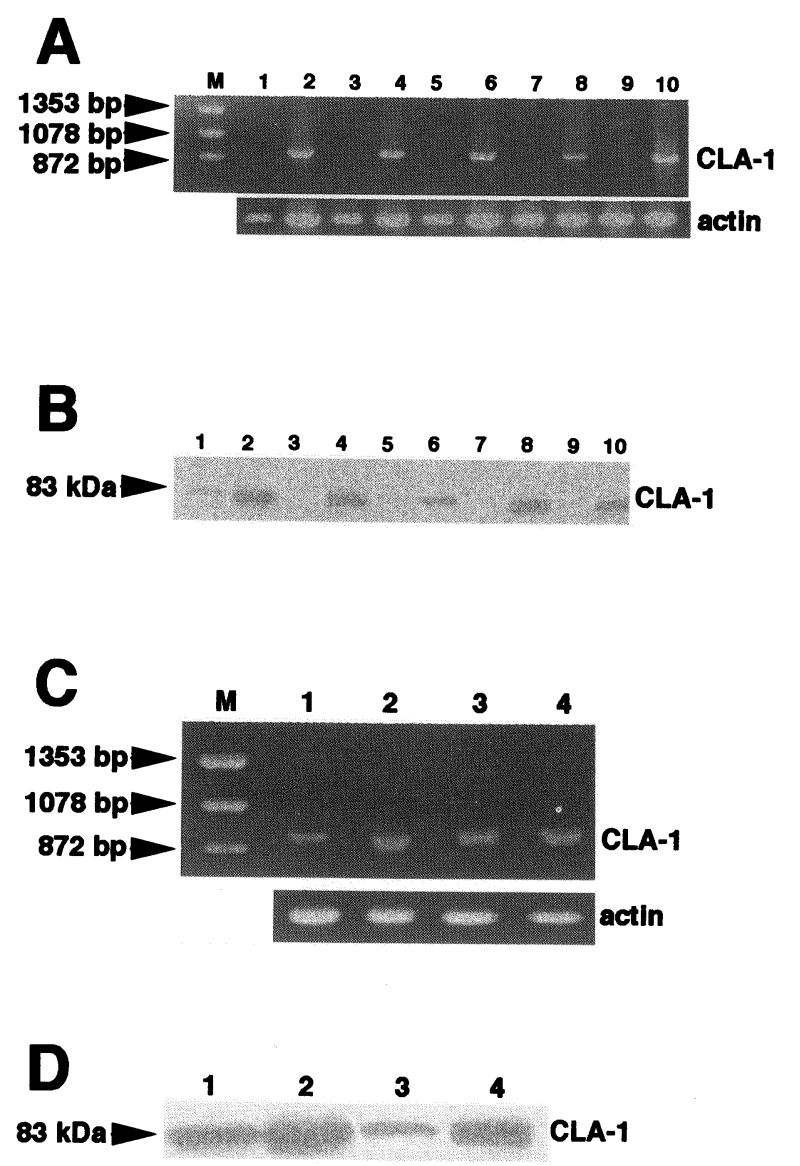

Fig. 2. CLA-1 expression in various adrenal tumors by RTPCR and Western blot analysis. (A) RT-PCR analysis of CLA-1 mRNA expression in Cushing's adenomas. Top, CLA-1; bottom, $\beta$-actin. Lane 1, 3, 5, 7,9 and 2, 4, 6, 8, 10 indicate Cushing's adjacent adrenal glands and Cushing's adenomas, respectively. (B) CLA-1 protein expression in Cushing's adenomas. Lane 1, 3, 5, 7, 9 and 2, 4, 6, 8, 10 indicate Cushing's adjacent adrenal glands and Cushing's adenomas, respectively. The position of CLA-1 on the gel is indicated by an arrow. (C) RTPCR analysis of CLA-1 mRNA expression in Conn's adenomas. Top, CLA-1; bottom, $\beta$-actin. Lane 1, 3 and 2, 4 indicate Conn's adjacent adrenal glands and Conn's adenomas, respectively. (D) CLA-1 protein expression in Conn's adenomas. Lane 1,3 and 2,4 indicate Conn's adjacent adrenal glands and Conn's adenomas, respectively. The position of CLA-1 on the gel is indicated by an arrow.

performed a RT-PCR analysis on human RNA samples. A positive control tested with the RTPCR showed a 380-bp-amplified product of $\beta$-actin in all samples. The CLA-1 gene expression was higher in tumor cells than that of non-tumor lesions of Cushing's syndrome. We also examined the protein expression of CLA-1 in human samples by Western blot (Fig. 2B). The signal was detected as a $83 \mathrm{kDa}$ protein, consistent with previous reports [7]. The relative amounts of CLA-1 protein expression in all specimens studied are summarized in Fig. 3. Western blot analysis showed a marked increase of CLA-1 expression in Cushing's adenomas to a level about $300 \%$ of that in controls (Conn's adenomas and pheochoromocytomas adjacent to adrenal glands from patients who had normal levels of serum ACTH). Conn's adenomas expressed CLA-1 at levels 2 times higher than that of controls. In Cushing's adenomas adjacent adrenal glands, CLA-1 expression was significantly lower than that of controls. Also, tumors of pheochromocytomas expressed little CLA-1 (data not shown).

\section{Immunohistochemical analysis of CLA-1 in adrenal gland}

To determine the cell type distribution of CLA-1 expression, we performed immunohistochemical staining of normal adrenal glands and adrenal tumors from patients with Cushing's syndrome. Fig. 4A shows CLA-1 immunostaining in the adrenal cortex but not in the adrenal medulla. CLA-1 staining was strongest in the outer zones fasciculata and zones glomerulosa of the adrenal cortex and was decreased in intensity toward the inner zones reticularis. Little CLA-1 staining was observed in adjacent adrenal tissues of Cushing's syndrome. In contrast, tumor cells of Cushing's syndrome revealed strong CLA-1 staining compared to the adjacent adrenal tissue. At higher magnification, immunostaining was most prominent in the plasma membrane of tumor cells (Fig. 4D). CLA-1 staining often completely encircled the tumor cell. Little or no staining was observed in non-tumor cells suggesting that CLA1 staining was specific to the cells producing excess steroid hormone.

\section{Discussion}

Cholesterol is the principal precursor for steroid biosynthesis in human steroidogenetic tissues [5]. Previously we have identified CLA-1 as a receptor 


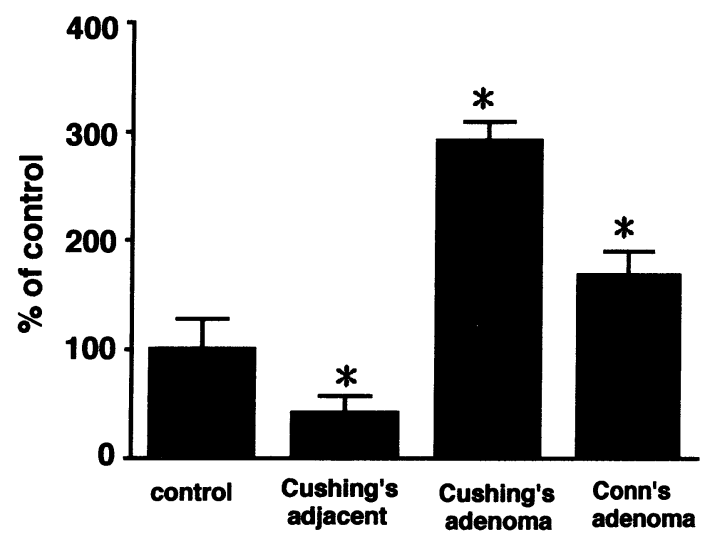

Fig. 3. Relative levels of CLA-1 expression in adrenal tumors. Proteins were extracted from tumors and non-tumor lesions of Cushing's syndrome, Conn's syndrome, pheochromocytoma. Ten $\mu \mathrm{g}$ of proteins were separated by SDS-PAGE, transferred to PVDF membrane, and detected by anti-CLA-1 antibody. The values were calculated from scanning the density of the signals. The levels of CLA-1 expression are presented as a percentage of control (adjacent adrenal glands of Conn's adenoma and pheochromocytoma). Results are the means \pm SEM. Statistical comparisons were made by one-way analysis of variance and the Student's $t$-test, with ${ }^{*} P<0.05$ considered significant.

for human HDL and have shown high levels of CLA-1 mRNA expression in steroidogenic tissues, especially the adrenal gland [7]. In this study, we have shown that SW-13 cells, a human adrenocortical cell line, have a high level of CLA-1 protein and also expressed a receptor for ACTH which can accelerate steroidogenesis in the adrenal gland. Furthermore, in this cell line, ACTH and its second messenger CAMP analogue stimulated CLA-1 protein expression. Immunohistochemistry and immunoblotting studies demonstrated that CLA-1 is specifically expressed in steroidogenic cells of the adrenal gland and that CLA-1 protein was expressed on the plasma membranes of the tumor cells of Cushing's syndrome.

ACTH causes secretion of cortisol from adrenocortical fasciculata cells and aldosterone from glomerulosa cells [16]. In general, ACTH action has been considered to be mediated via cAMP [17]. Previous reports have shown that ACTH is associated with an increase in HDL binding and selective cholesterol ester uptake from HDL in rat adrenal glands [3]. Kovanen et al. demonstrated that hypolipoproteinemia and ACTH together were both required to induce a dramatic elevation in adrenal ${ }^{125}$ I-HDL uptake in the mouse [18]. A recent report showed that the accumulation of CLA-1 mRNA in primary cultures of human normal adrenocortical cell is up-regulated by ACTH and cAMP [19], and we have confirmed the effects of ACTH on CLA-1 protein expression in a human adrenocortical cell line. In non-tumor lesions, excess of glucocorticoid, which suppresses the endogenous ACTH levels and the adrenocortical steroid production, dramatically decreased CLA-1 protein expression. There was a strong correlation between adrenal gland steroidogenesis and the ACTH concentration. Although ACTH induced CLA-1 expression in SW-13 cells which originated from an adrenocortical tumor, the contribution of CLA-1 in producing steroid hormones is still uncertain. Whether or not this role of the receptor is important in lipid transport in humans remains to be determined.

Yaguchi et al. recently reported that HDL rather than low density lipoprotein (LDL) is thought to be the preferred lipoprotein as a source of steroidogenic substrate cholesterol in bovine adrenal fasciculo-reticularis cells [20]. However many studies have suggested that the major source of cholesterol for steroidogenesis in humans is LDL, but the relative importance of LDL and HDL is difficult to assess under in vivo conditions [5]. Certainly in situations where LDL concentrations are very low (e.g. in hypobetalipoproteinemia), adrenal function remains adequate although less able to respond to stress. Under these situations, HDL selective cholesterol ester uptake via CLA-1 might become physiologically important. Although LDL receptors were also up-regulated in tumors of Cushing's syndrome [5], our results clearly indicate that CLA-1 might play an important role in delivery of cholesterol to the steroidogenesis tissues. This is supported by a recent report demonstrating that an antibody directed against the mouse homologue, SR-B1, inhibits steroid biosynthesis in mouse adrenocortical cells [21]. Another report demonstrated a marked decrease of adrenal gland cholesterol content is observed in SR-B1 knock-out mice [22].

The uptake of cholesterol and steroidogenesis in Cushing's adenoma cells are autonomous and, thus, insensitive to the reduction of the ACTH concentration. Previous studies with adrenal 

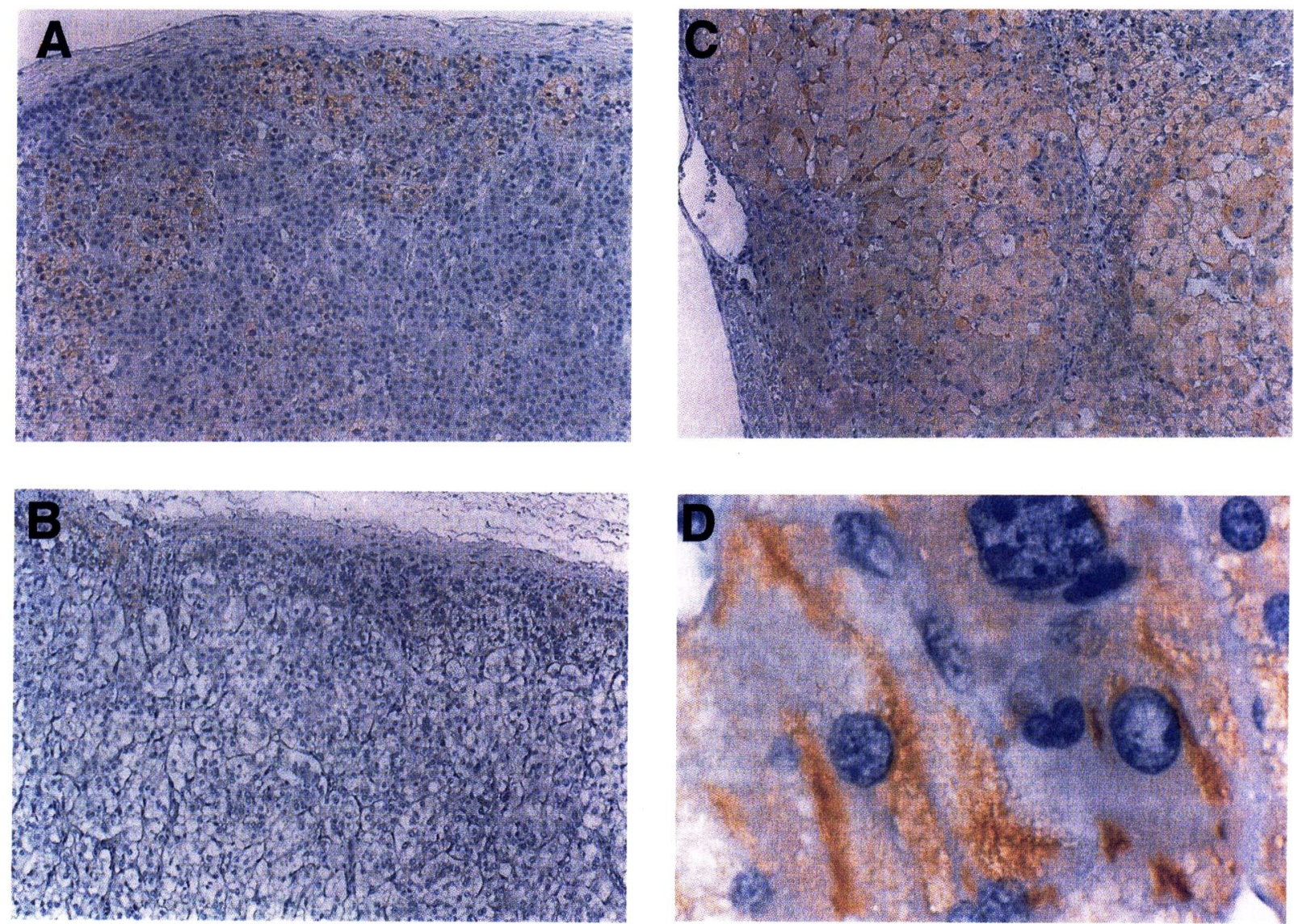

Fig. 4. Immunohistochemical localization of CLA-1 in adrenal gland and Cushing's adenoma. (A) Normal adrenal gland: CLA-1 staining was positive in zones fasciculata of the adrenal cortex, but not in the adrenal medulla. (B) Cushing's adjacent adrenal gland, (C, D) Cushing's adenoma. Representative fields were photographed at low $(x$ 100 , panels A, B, C) or high ( $\times 1000$, panel D) magnification.

glands obtained from patients with Cushing's syndrome have shown that evidence of autonomy of the adrenal gland in dynamic tests in vivo is in most cases reflected by a lowered responsiveness of the cells to ACTH administration [23]. Although previous reports revealed that CLA-1 mRNA expression in Cushing's and Conn's adenomas is similar or lower than that in normal adrenal glands [19], CLA-1 protein expression on adenomas of Cushing's syndrome was significantly increased compared to that on adjacent adrenal glands of Conn's adenoma and pheochoromocytoma from patients who had normal levels of serum ACTH in this study. This may be due to the different analyse employed for detecting the mRNA or the protein expression.
In summary, this study shows that CLA-1 as a receptor for HDL is overexpressed in human adrenocortical tumors at the protein level. CLA-1 is up-regulated by ACTH and cAMP in SW-13 cells. Together, our results supported the possibility that CLA-1 might provide HDL cholesterol as a substrate to steroidogenesis in the adrenal gland.

\section{Acknowledgments}

We are grateful to Drs. D. Steinberg, O. Quehenberger, and D. Bird (University of California, San Diego) for their invaluable discussions, and to Kazuko Yamaji for her technical assistance. 


\section{References}

1. Acton SL, Scherer PE, Lodish HF, Krieger M (1994) Expression cloning of SR-BI, a CD36-related class B scavenger receptor. J Biol Chem 269: 21003-21009.

2. Acton S, Rigotti A, Landschulz KT, Xu S, Hobbs H $H$, Krieger M (1996) Identification of scavenger receptor SR-BI as a high density lipoprotein receptor. Science 271: 518-520.

3. Landschulz KT, Pathak RK, Rigotti A, Krieger M, Hobbs HH (1996) Regulation of scavenger receptor, class B, type I, a high density lipoprotein receptor, in liver and steroidogenic tissues of the rat. J Clin Invest 98: 984-995.

4. Rigotti A, Edelman ER, Seifert P, Iqbal SN, DeMattos RB, Temel RE, Krieger M, Williams DL (1996) Regulation by adrenocorticotropic hormone of the in vivo expression of scavenger receptor class B type I (SR-BI), a high density lipoprotein receptor, in steroidogenic cells of the murine adrenal gland. J Biol Chem 271: 33545-33549.

5. Gwynne JT, Srauss JF (1982) The role of lipoproteins in steroidogenesis and cholesterol metabolism in steroidogenic gland. Endocr Rev 3: 299-328.

6. Calvo D, Vega MA (1993) Identification, primary structure, and distribution of CLA-1, a novel member of the CD36/LIMPII gene family. J Biol Chem 268: 18929-18935.

7. Murao K, Terpstra V, Green SR, Kondratenko N, Steinberg D, Quehenberger O (1997) Characterization of CLA-1, a human homologue of rodent scavenger receptor $\mathrm{BI}$, as a receptor for high density lipoprotein and apoptotic thymocytes. J Biol Chem 272: 17551-17557.

8. Gwynne JT, Hess B (1980) The role of high density lipoproteins in rat adrenal cholesterol metabolism and steroidogenesis. J Biol Chem 255: 10875-10883.

9. Leichter SB, Daughaday WH (1974) Massive steroid excretion and hypocholesterolemia with an adrenal adenoma. Report of a case. Ann Intern Med 81: 638640.

10. Chomczynski P, Sacchi N (1987) Single-step method of RNA isolation by acid guanidinium thiocyanatephenol-chloroform extraction. Anal Biochem 162: 156-159.

11. Mizobuchi M, Murao $K$, Takeda R, Kakimoto $Y$ (1994) Tissue specific expression of isoaspartyl protein carboxyl methyltransferase gene in rat brain and testis. J Neurochem 62: 322-328.

12. Fujita T, Yamaji $Y$, Sato $M$, Murao K, Takahara J (1994) Gene expression of somatostain receptor subtypes, SSTR1 and SSTR2, in human lung cancer cell lines. Life Sciences 55: 1797-1806.

13. Lebrethon MC, Naville D, Begeot M, Saez JM (1994)
Regulation of corticotropin receptor number and messenger RNA in cultured human adrecortical cells by corticotropin and angiotensin II. J Clin Invest 93: 1828-1833.

14. Jokinen EV, Landschuz KT, Wyne KL, Ho YK, Frykman PK, Hobbs HH (1994) Regulation of the very low density lipoprotein receptor by thyroid hormone in rat skeletal muscle. J Biol Chem 269: 26411-26418.

15. Guo Q, Penman M, Trigatti BL, Krieger M (1996) A single point mutation in epsilon-COP results in temperature-sensitive, lethal defects in membrane transport in a Chinese hamster ovary cell mutant. J Biol Chem 271: 11191-11196.

16. Saruta T, Cook R, Kaplan NM (1972) Adrenocortical steroidogenesis: studies on the mechanism of action of angiotensin and electrolytes. J Clin Invest 51: 2239-2245.

17. Graham-Smith DG, Butcher RW, Ney RL, Sutherland EW (1967) Adenosine 3',5'-monophosphate as the intrecellular mediator of action of adrenocorticotropic hormone on the adrenal cortex. J Biol Chem 242: 5535-5541.

18. Kovanen PT, Schneider WJ, Hillman GM, Goldstein JL, Brown MS (1979) Separate mechanisms for the uptake of high and low density lipoproteins by mouse adrenal gland in vivo. J Biol Chem 254: 54985505.

19. Liu J, Voutilainen R, Heikkila P, Kahri AI (1997) Ribonucleic acid expression of the CLA-1 gene, a human homolog to mouse high density lipoprotein receptor SR-BI, in human adrenal tumors and cultured adrenal cells. J Clin Endocrinol Metab 82: 2522-2527.

20. Yaguchi H, Tsutsumi K, Shimono K, Omura M, Sasano H, Nishikawa T (1998) Involvement of high density lipoprotein as substrate cholesterol for steroidogenesis by bovine adrenal fasciculoreticularis cells. Life Sci 62: 1387-1395.

21. Temel RE, Trigatti B, DeMattos RB, Azhar S, Krieger M, Williams DL (1997) Scavenger receptor class B, type I (SR-BI) is the major route for the delivery of high density lipoprotein cholesterol to the steroidogenic pathway in cultured mouse adrenocortical cells. Proc Natl Acad Sci USA 94: 13600-13605.

22. Rigotti A, Trigatti BL, Penman M, Rayburn H, Herz J, Krieger M (1997) A targeted mutation in the murine gene encoding the high density lipoprotein (HDL) receptor scavenger receptor class $B$ type I reveals its key role in HDL metabolism. Proc Natl Acad Sci USA 94: 12610-12615. 
23. Lamberts SW, Zuiderwijk J, Uitterlinden P, Blijd JJ, Bruining HA, de Jong FH (1990) Characterization of adrenal autonomy in Cushing's syndrome: A comparison between in vivo and in vitro responsiveness of the adrenal gland. J Clin Endocrinol 70: 192-199. 